\title{
The return of chloroquine-sensitive Plasmodium falciparum parasites in Jazan Region, Southwestern Saudi Arabia over a decade after the adoption of artemisinin-based combination therapy: analysis of genetic mutations in the pfcrt gene
}

Aymen M. Madkhali

Jazan University Faculty of Applied Medical Science

Ahmed A. Abdulhaq

Jazan University Faculty of Applied Medical Science

Wahib M. Atroosh

University of Malaya Faculty of Medicine

Ahmad Hassn Ghzwani

Jazan University

Khalid Ammash Zain

Jazan University

Khalid Y. Ghailan

Jazan University Faculty of Public Health and Tropical Medicine

Hassan A. Hamali

Jazan University Faculty of Applied Medical Science

Abdullah A. Mobarki

Jazan University Faculty of Applied Medical Science

Zaki M. Eisa

Saudi Arabia Ministry of Health

Yee-Ling Lau

University of Malaya Faculty of Medicine

Hesham Al-Mekhlafi ( $\sim$ halmekhlafi@yahoo.com )

Jazan University https://orcid.org/0000-0003-2582-7410

\section{Research Article}

Keywords: Chloroquine, drug resistance, infectious diseases, malaria, pfcrt, Plasmodium falciparum, Saudi Arabia

Posted Date: September 14th, 2021

DOI: https://doi.org/10.21203/rs.3.rs-812480/v2

License: (c) (i) This work is licensed under a Creative Commons Attribution 4.0 International License. Read Full License 


\section{Abstract}

This study investigated the polymorphism in the $P$. falciparum chloroquine resistance transporter (pfcrt) gene 11 years after chloroquine (CQ) cessation in Jazan region, southwestern Saudi Arabia. Two hundred and thirty-five $P$. falciparum isolates were amplified to detect mutations in the pfcrt gene. The pfcrt 76T molecular marker for CQ resistance was detected in $66.4 \%$ (156/235) of the isolates, while the K76 CQ-sensitive wild type was detected in $33.6 \%$. The pfcrt 74I and pfcrt 75E point mutations were each found to be present in $56.2 \%$ of isolates, while only four isolates (1.7\%) were found to carry the pfcrt $72 \mathrm{~S}$ mutation. Moreover, four pfcrt haplotypes were identified: the CVIET triple-allele (56.2\%), SVMET double-allele (1.7\%), and CVMNT single-allele (8.5\%) mutant haplotypes, and the CVMNK wild haplotype (33.6\%). The analysis also revealed significant associations between the prevalence of mutant $p f c r t$ alleles and haplotypes and the age group, governorate, and nationality of the patients as well as the parasitaemia level $(P<0.05)$. The findings provide evidence of the potential re-emergence of CQ-susceptible $P$. falciparum strains in Jazan region over a decade after CQ discontinuation, with about one third of the isolates analysed carrying the pfcrt K76 CQ-sensitive wild allele and the CVMNK ancestral wild haplotype. Although the reintroduction of CQ cannot be recommended at present in Saudi Arabia, these findings support the rationale for a potential future role for CQ in malaria treatment. Therefore, continuous molecular and in-vitro monitoring mutations of pfcrt polymorphism in Jazan region is highly recommended.

\section{Introduction}

Malaria, a mosquito-borne disease transmitted by the bite of the female Anopheles mosquito, is a leading cause of morbidity and mortality worldwide, especially in the tropics and subtropics. Despite global success in reducing the malaria burden over the last several decades and the successful elimination of malaria from more than 100 countries, the disease is still endemic in 106 countries (WHO 2020; Feachem et al. 2019). Antimalarial drug resistance has emerged as one of the most critical threats hampering the global efforts to control and eliminate malaria. For many decades, chloroquine (CQ) was used extensively as the first-line treatment for uncomplicated malaria. However, in the late 1950s, CQ-resistant Plasmodium falciparum malaria emerged independently in Southeast Asia (Thai-Cambodian border) and in South America (Colombia) (Payne 1987). Subsequently, resistant $P$. falciparum strains spread steadily across different countries throughout Southeast Asia and into India, as well as across South America in the 1960s and 1970s, and then spread to Africa in the late 1970s with confirmed treatment failures reported in Kenya and Tanzania (Fogh et al. 1979; Wellems and Plowe 2001). Yet, despite the increasing spread of CQ resistance worldwide, CQ remained the first-line treatment for malaria until the 2000s.

It is well documented that $\mathrm{CQ}$ resistance is associated with specific mutations in polymorphism of the $P$. falciparum chloroquine resistance transporter ( $p f c r t$ ) gene located on chromosome 7 (Roux et al. 2021). The cluster of mutations at codons 72 to 76 of the pfcrt gene has been found to be associated with the evolution of three main distinct haplotypes/genotypes: 1) the ancestral CQ-susceptible haplotype, which is found in CQ-sensitive isolates and referred to as $\mathrm{C}_{72} \mathrm{~V}_{73} \mathrm{M}_{74} \mathrm{~N}_{75} \mathrm{~K}_{76} ; 2$ ) the double mutated

haplotype $S_{72} V_{73} M_{74} N_{75} T_{76}$, which is widely prevalent in Latin America and Asia; and 3) the triple-mutated haplotype $C_{72} V_{73} I_{74} E_{75} T_{76}$, which predominates in Africa and Southeast Asia (mutated alleles are shown in bold) (Ariey et al. 2006; Awasthi et al. 2012). Moreover, other mutated haplotypes such as $\mathrm{C}_{72} \mathrm{~V}_{73} \mathrm{M}_{74} \mathrm{E}_{74} \mathrm{~T}_{76}, \mathrm{C}_{72} \mathrm{~V}_{73} \mathrm{M}_{74} \mathrm{~N}_{75} \mathrm{~T}_{76}$ and $\mathrm{S}_{72} \mathrm{~V}_{73} \mathrm{I}_{74} \mathrm{E}_{75} \mathrm{~T}_{76}$ have been reported in other regions (Awasthi et al. 2012; Atroosh et al. 2016). Studies have also revealed that a point mutation at codon 76 of the pfcrt gene, which occurs as a result of lysine amino acid substitution by threonine (wild-type K to mutant T-K76T), is highly associated with CQ resistance and clinical CQ treatment failure (Djimdé et al. 2001; Wicht et al. 2020).

In Saudi Arabia, CQ resistance was first recorded in 1992 when reports on clinical treatment failures increased (Malik et al. 1997; Alrajhi et al. 1999; Al Arishi et al. 2001). Subsequently, the malaria drug policy in the country was scaled up in 2007 and CQ was replaced with ACT, with artesunate plus SP as a first-line treatment and artemether-lumefanthrine as the second-line for the treatment of uncomplicated falciparum malaria (Madkhali et al. 2020; MOH 2018). Since then, some molecular studies have revealed a high prevalence of pfcrt 76T mutations in isolates from different areas of the country (Al Harthi, 2007; Bin Dajem and Al-Qahtani 2010; Bin Dajem et al. 2012). However, those studies only evaluated the mutations at codon 76 of the pfcrt gene, so data on mutations at other codons as well as on pfcrt-related haplotypes are very limited. Interestingly, some previous studies conducted in Africa reported the reemergence of CQ-sensitive $P$. falciparum strains several years following the discontinuation of CQ use and the switching of malaria treatment to ACT (Laufer et al. 2006; Dagnogo et al. 2018; Balikagala et al. 2020). 
The paucity of data on the status of pfcrt point mutations in Saudi Arabia after 2012 and the potential re-emerging sensitivity to CQ motivated the current study to investigate the frequency and distribution of pfcrt point mutations in $P$. falciparum isolates in the malaria-endemic Jazan region, 11 years after the ban on the use of $C Q$ to treat uncomplicated falciparum malaria.

\section{Materials And Methods}

\section{Study design and area}

The current study was a cross-sectional hospital-based study conducted in Jazan region that targeted febrile patients who were suspected to have malaria. Jazan region is located $16^{\circ} 17^{\prime}$ North, $42^{\circ} 43^{\prime}$ East in the southwestern part of Saudi Arabia. The region is bordered by Yemen to the south and by the Red Sea to the west. The region comprises 17 governorates, extends over a total area of $11671 \mathrm{~km}^{2}$ and is home to a population of about 1.4 million (GASTAT 2021).

Topologically speaking, Jazan region can be divided into three different areas: the highlands, as represented by the Faifa mountains (which constitute part of the As Sarawat mountain range) at an elevation of over $2000 \mathrm{~m}$ above sea level, the foothills at an elevation of $400-600 \mathrm{~m}$ and the coastal plains alongside the Red Sea at an altitude of less than $400 \mathrm{~m}$. The aggregated rainfall varies between less than $100 \mathrm{~mm} /$ year on the coastal plains and more than $300 \mathrm{~mm} /$ year in the highlands (Lashin and Al Arifi 2012). The region also contains some valleys, as well as a number of streams and dams that act as a source of drinking and irrigation water (MEWA 2019). Malaria is endemic in Jazan region, with a few foci of malaria transmission, and transmission peaks between December and March (Madkhali et al. 2020). Anopheles arabiensis is considered the principal malaria vector in the region; however, other species including An. sergentii, An. dthali and An. stephensi have also been recorded (Alahmed et al. 2019; Snow et al. 2013).

\section{Study population}

Febrile individuals who presented at selected healthcare facilities in Jazan region and tested positive for malaria between April and December 2018 were invited to participate in the current study, irrespective of their gender, nationality and age. The participants' demographic data (residency, gender, age and nationality) were collected through the use of a semi-structured questionnaire or from the patients' medical records. This was an exploratory descriptive study that did not necessitate the calculation of a power and sample size. However, the required sample size was calculated based on the WHO's guidelines (Lwanga et al. 1991). Accordingly, at the high prevalence of pfcrt 76T mutation previously reported, a 95\% confidence level and a $5 \%$ significance level, the calculation yielded a minimum sample size of $138 P$. falciparum isolates. During the study period, a total of 530 participants were screened for malaria, from whom 250 P. falciparum isolates were collected for the molecular examination of point mutations in the pfcrt gene. Subsequently, pfcrt gene were successfully amplified from 235 of those isolates and used for the data analysis.

\section{Blood sampling and examination}

A blood sample of approximately 2-3 $\mathrm{ml}$ was obtained from each patient and put into an EDTA tube labelled clearly with the participant's identification number, name, gender and age. Promptly thereafter, both thin and thick blood films/smears were prepared for each blood sample and stained with Giemsa stain in accordance with a standard protocol (WHO 2015). Additionally, dried blood spots were prepared on $3 \mathrm{MM}$ Whatman ${ }^{\circledR}$ filter paper and kept in labelled, separate, sealed plastic bag for molecular analysis. The thin and thick stained blood smears were examined microscopically for the presence of Plasmodium parasites and identification of species. From the thick blood film, the parasitaemia (also called parasite density) was estimated by counting the asexual stages of the Plasmodium parasite against 200 white blood cells (WBCs), under the assumption of an average WBC count per $\mu \mathrm{l}$ of blood of 8000 (WHO 2015; Al-Mekhlafi et al. 2021). Some archived malaria-positive slides for the patients examined during the study period were also obtained from the participating healthcare facilities and re-examined for parasite species and parasite density.

\section{Molecular analysis}

Extraction of DNA from dried blood spots was done using a Qiagen blood and tissue kit (QIAGEN, DNeasy ${ }^{\circledR}$ Blood \& Tissue Kit, Cat. no. 69506, Germany) following the manufacturer's instructions provided in the kit. The extracted DNA was eluted using $100 \mu \mathrm{l}$ of $A E$ elution buffer, which contained $10 \mathrm{mM}$ Tris-Cl; $0.5 \mathrm{mM}$ EDTA; at pH 9.0 and was kept at $-20^{\circ} \mathrm{C}$ until used. 


\section{Detection of pfcrt point mutations}

The genomic DNA of $P$. falciparum was subjected to the polymerase chain reaction and restriction fragment length polymorphism (PCR-RFLP) technique in order to detect mutations at codons 72 to 76 of the pfcrt gene, according to an established protocol (Djimdé et al. 2001). Restriction enzyme (RE) digestion was performed in $20 \mu \mathrm{l}$ of reaction mixture that included $6-8 \mu \mathrm{l}$ of PCR product, 1 unit of the specific RE (New England Biolabs Inc., UK) and 1X of the specific buffer provided in the RE kit. The reaction mixture was then incubated for $15-60$ minutes at $37^{\circ} \mathrm{C}$ or $50^{\circ} \mathrm{C}$ (based on the RE) following the manufacturer's instructions. Then, the mixture was subjected to gel electrophoresis using $4 \%$ of TAE-buffered agarose gel stained with Sybr ${ }^{\circledR}$ safe DNA gel stain (Invitrogen, USA). The RE digestion products were visualised under UV light using a Molecular Imager Gel Doc XR System (Bio-Rad, Hercules, CA,

USA). The primer sequences, PCR thermal conditions, and RE used for the detection of point mutations of the pfcrt gene have been described previously (Atroosh et al. 2016).

The genomic DNA of $P$. falciparum reference strains that were used by the current study as positive controls were provided by the Malaria Research and Reference Reagents Resources Center (MR4, ATCCW, Manassas, VA, USA). The genomic DNA of $P$. falciparum strain Dd2 (MRA-150G) was utilised as a positive control for the pfcrt mutated types, while the $P$. falciparum reference strain 3D7 (MRA-102G) was utilised as a positive control for the wild types.

\section{Statistical data analysis}

Statistical data analysis was done using IBM SPSS v20 (IBM Corp., NY, USA). Categorical variables, i.e. the pfcrt point mutations and haplotypes at the studied codons (dependent variable) and other variables such as gender, nationality and age group were described as frequencies and proportions. On the other hand, mean \pm standard deviation (SD) or median (interquartile range, IQR) were used to describe quantitative variables namely age (years) and parasite density. Associations between the dependent variables and the explanatory variables were examined using the Chi-square test or Fisher's exact test, where appropriate. The significance level of all tests was set at $P<0.05$.

\section{Results}

A total of $235 P$. falciparum-positive patients aged between 2 and 78 years, with a mean age of $30.5 \pm 11.6$ years, were included in the current study. The majority of the participants ( $82.1 \%$ ) were male and $17.9 \%$ were female. As regards residency, $69.8 \%$ and $30.2 \%$ of the participants were from urban and rural areas, respectively. During the study period, malaria-positive samples were collected from all the governorates of Jazan except Altwal, Alraith, Haroob, Fayfa highlands and Farasan Island. The highest percentage (19.1\%) of the isolates was from Baysh governorate followed by Jizan (12.8\%) and Alharth (11.5\%) governorates. About one third (34\%) of the participants were Saudi and 66\% (155/235) were non-Saudi, and 44.5\% (69/155) of the non-Saudi participants were from Yemen. Table 1 displays the general characteristics of the patients who participated in the study.

\section{Prevalence and distribution of pfort mutations and haplotypes}

Table 2 shows the frequency distribution of the pfcrt gene point mutations and haplotypes/genotypes in the study sample. Of the 250 isolates subjected to the initial molecular analysis, 235 (94\%) were successfully amplified for the pfcrt gene. The pfcrt 76T CQresistant mutant type was found in $66.4 \%$ (159/235) of the isolates, while $33.6 \%$ of the isolates were found to be carrying the K76 CQsensitive wild type. The pfcrt 74I and pfcrt 75E point mutations were each detected in $56.2 \%$ of the isolates. On the other hand, isolates were found of all wild types for the pfcrt 73 codon, while only four isolates (1.7\%) had pfcrt $72 \mathrm{~S}$ mutated alleles.

With regard to the haplotypes/genotypes, four pfcrt 72-76 haplotypes were found to be circulating in the study area. The haplotype identified as having the highest prevalence was the CVIET triple-allele mutated haplotype (56.2\%), while the wild haplotype, CVMNK was found in 79 isolates (33.6\%). In addition, single-allele CVMNT and double-allele SVMET mutated haplotypes were found in $8.5 \%$ and $1.7 \%$ of the study isolates.

\section{Associations of pfcrt mutations with demographic factors and parasitaemia}

Table 3 shows the associations between the pfcrt point mutations and related haplotypes and the participants' demographic factors and parasitaemia level. In respect of age, a significantly higher percentage of isolates were found to be carrying the mutated pfcrt 76T allele among patients aged $\geq 30$ years $(72.4 \%, 89 / 123)$ as compared to patients aged $<30$ years $(59.8 \%, 67 / 112)\left(\chi^{2}=4.128 ; \mathrm{df}=1\right.$; 
$P=0.042)$. Also, the percentage of isolates carrying the CVMNK wild haplotype from patients aged $<30$ years $(40.2 \%)$ was significantly higher than the percentage in the isolates from those aged $\geq 30$ years $(27.6 \%)(P=0.042)$.

In regard to parasite density, the percentages of pfcrt 74I and pfcrt 75E mutated alleles were significantly higher $\left(\chi^{2}=4.657\right.$; df $=1 ; P=0.031)$ in isolates from patients with low parasitaemia $(64.1 \%, 66 / 103)$ as compared to those from patients with moderate-tohigh levels of parasitaemia $(50 \%, 66 / 132)$. Moreover, a significantly higher percentage of the CVIET mutated haplotype (also known as the classical old-world African/Southeast Asian haplotype) was observed in isolates from patients with low parasitaemia as compared to those from patients with moderate-to-high parasitaemia $(64.1 \%, 50 \% ; P=0.031)$.

As for nationality, the pfcrt 76T allele was observed to be present predominantly among patients from Yemen (94.2\%) followed by those from Pakistan (65.5\%) and then among Saudi nationals (58.8\%) (Table 3). Interestingly, higher percentages of isolates carrying the mutated pfort 76T allele and CVIET mutated haplotype were found in isolates from non-Saudi patients $(70.3 \%$ and $57.4 \%$, respectively) as compared to their Saudi counterparts (58.8\% and $53.8 \%$, respectively). However, the differences were not statistically significant $(P>0.05)$. In other words, a higher percentage of the wild-type $\mathrm{K} 76$ allele was observed in isolates from Saudi (41.2\%) as compared to non-Saudi (29.7\%) patients.

On the other hand, there were significant variations across governorates in the pfcrt point mutations $\left(\chi^{2}=23.040 ; \mathrm{df}=11 ; P=\right.$ 0.017) and in haplotypes $\left(\chi^{2}=22.486 ; \mathrm{df}=11 ; P=0.021\right)$ (Fig. 1 and Supplementary Table S1). The highest percentage of the mutant pfcrt $76 \mathrm{~T}$ allele was reported in isolates from Aldair governorate $(95.7 \%, 22 / 23)$ followed by isolates from Baysh $(77.8 \%, 35 / 45)$ and Sabya $(76.9 \%, 10 / 13)$ governorates, whereas the highest percentage of the pfcrt K76 wild allele and the respective CVMNK haplotype were found in isolates from Samtah $(63.2 \%, 12 / 19)$ followed by Ahad Almsariha $(50 \%, 2 / 4)$ governorate. Also, the percentage of the CVIET haplotype was highest in isolates from Aldair $(91.3 \%, 21 / 23)$ followed by Dhamad $(70 \%, 7 / 10)$ governorate.

\section{Discussion}

Given the ongoing challenges associated with the elimination of this serious disease, the current study investigated the frequency and distribution of $p f c r t$ gene point mutations in $P$. falciparum isolates collected from Jazan region in southwestern Saudi Arabia, just over a decade after the cessation of CQ use and the adoption of ACT for the treatment of uncomplicated falciparum malaria.

The results revealed that the pfcrt 76T point mutation (the most important mutation linked with CQ resistance) was present in about two thirds $(66.4 \%)$ of the examined isolates, whereas about one third $(33.6 \%)$ of the isolates were found to carry the K76 wild variant. The results also showed a higher percentage of the wild-type K76 allele of the pfort gene in isolates from Saudi (41.2\%) as compared to those from non-Saudi (29.7\%) patients, and importantly, there were also some locally transmitted isolates (autochthonous malaria). Therefore, these results indicate the potential return of CQ-sensitive strains in Saudi Arabia.

Although CQ resistance and clinical treatment failures in the country were reported in the early 1990s (Malik et al. 1997), molecular studies on pfcrt were not conducted until in the mid-2000s. Prior to those studies, the CQ treatment failure rates varied between 12\% and 38\% (Alrajhi et al. 1999; Malik et al. 1998; Ghalib et al. 2001). The first molecular study on pfcrt gene polymorphism was conducted in 2007 and showed that about $90 \%$ of $19 P$. falciparum isolates from Jazan region carried the pfcrt 76T mutated allele (Al Harthi et al. 2007). Later, other studies found the 76T mutated allele of pfcrt in 100\% of 121 P. falciparum isolates from both the Jazan and Aseer regions (Bin Dajem and Al-Qahtani 2010; Bin Dajem et al. 2011). Likewise, a comprehensive previous study found that $99 \%$ of 165 P. falciparum isolates from Jazan were carrying the pfcrt 76T mutated allele (Bin Dajem et al. 2012). A more recent study detected the pfcrt 76T mutation in only four out of 13 (30.7\%) P. falciparum isolates from Taif province, about $720 \mathrm{~km}$ north of Jazan, while the remainder (eight isolates) were carrying the wild allele (Soliman et al. 2018). However, the results of that study are limited by the very small sample size.

Overall, the withdrawal of CQ and the adoption of ACT treatments in Saudi Arabia in 2007 might explain the return of CQsensitive isolates, as identified by the current study. Yet, there is a dearth of information on the frequency of pfcrt point mutations in Saudi Arabia. Therefore, the hypothesis proposed herein that CQ-sensitive strains have reappeared in the country requires further evaluation. It was suggested that removing drug pressure has allowed re-expansion of CQ-sensitive parasites that survived during the period when chloroquine was used (Babiker et al. 2009; Laufer et al. 2010; Mulenga et al. 2021). Moreover, other explanations for the re-emergence of CQ-sensitive parasites include back-mutations in the CQ-resistant allele of the pfcrt gene (Fidock et al.

2000) or propagation of a single or a few imported CQ-sensitive parasites with increased survival fitness over the CQ-resistant 
parasites (Laufer et al. 2010). Therefore, microsatellite loci analyses are essential to compare the genetic similarity among CQsusceptible and among CQ-resistant parasites as well as between parasite populations circulating before and after the official banning of $\mathrm{CQ}$ as a falciparum malaria chemotherapy in Saudi Arabia.

Interestingly, some previous studies, exclusively from Africa, have demonstrated the return of CQ-sensitive P. falciparum strains several years after the cessation of CQ use and have suggested that CQ might once again be effective. In 1994, Malawi was the first country in Africa to withdraw CQ, and 12 years later molecular markers of CQ resistance had completely disappeared and the K76 wild type had reached fixation (Kublin et al. 2003; Frosch et al. 2014). Subsequently, a randomised clinical trial demonstrated the superior efficacy of CQ against uncomplicated falciparum malaria in Malawi, with a cumulative efficacy of $99 \%$ as compared to $21 \%$ for SP, and also detected the K76 wild type in all isolates (Laufer et al. 2006). Similarly, in 1998, Kenya scaled up its national malaria drug policy and switched from CQ to SP. Subsequently, a study showed increasing rates of the K76 wild type until 2006 (Mwai et al. 2009). However, another study conducted in western Kenya, where CQ use continued despite a national-level policy change, showed that the prevalence of mutant type pfcrt 76T increased significantly, from 76\% in 2001 to $94 \%$ in 2007 (Shah et al. 2015). Moreover, the reemergence of CQ-sensitive falciparum malaria has been reported in other African countries, including Sudan (Bakhiet et al. 2019), Tanzania (Alifrangis et al. 2009; Mohammed et al. 2013), Ethiopia (Mekonnen et al. 2014), Liberia (Otienoburu et al. 2016), Côte d'Ivoire (Dagnogo et al. 2018) and Uganda (Balikagala et al. 2020).

Looking at those countries geographically closer to Saudi Arabia, the prevalence of the mutant pfcrt 76T allele in the neighbouring endemic country of Yemen was reported to be as high as $100 \%$ several years after switching from CQ to ACT in 2009 (Al-Mekhlafi et al. 2011; Alareqi et al. 2016; Atroosh et al. 2016). Similar findings were reported for Pakistan (Khattak et al. 2013; Khan et al. 2020). These findings are consistent with those of the current study, which showed that the highest percentage of the mutant pfcrt 76T allele was in the isolates from Yemeni (94.2\%) followed by Pakistani (65.5\%) patients, as compared to those from other nationalities. Bearing in mind that over 12 million foreign nationals are employed in Saudi Arabia, and that the majority of them are from malaria-endemic countries such as Pakistan, Yemen, Sudan and Ethiopia (US-SABC 2020), and that malaria in Jazan region is mostly imported, with a very low number of locally transmitted cases reported (Al-Mekhlafi et al. 2021), it would be desirable to carry out further studies on a larger number of samples to carefully evaluate pfcrt polymorphism according to nationality and source of case.

The findings of the current study also showed that the percentage of CVIET triple-mutant haplotype in the studied isolates was $56.2 \%$, while about only one third (33.6\%) of the isolates harboured the CVMNK wild haplotype. The only previous study that reported the presence of pfcrt-related haplotypes in Saudi Arabia was conducted in Jazan region and showed that almost all the studied isolates $(99 \% ; 163 / 165)$ harboured the triple-mutant CVIET haplotype (Ben Dajem et al. 2012). The reduction in the prevalence of this haplotype in the region is attributed to the re-emergence of the pfcrt K76 wild allele reported by the current study. Similar findings have also been reported in some African countries that witnessed a partial return of the pfcrt K76 wild allele (Alifrangis et al. 2009). The CVIET haplotype which originated in Southeast Asia is the most common haplotype in some African and Middle Eastern countries, including Yemen (Al-Hamidhi et al. 2013), and Sudan (Gadalla et al. 2010), whereas the SVMNT double mutant haplotype has remained the predominant haplotype in Asian countries close to the Arabian Peninsula, such as Pakistan (Sahar et al. 2015) and Iran (Ursing et al. 2006). These findings are consistent with the current study which found that the SVMNT haplotype was present only in isolates from Pakistani patients, while the percentage of the CVIET haplotype was highest in isolates from Yemeni patients.

The current study also examined the associations of point mutations and haplotypes in the pfort gene with the participants' demographic factors and parasitaemia. The results showed that the percentage of the pfcrt 76T mutation and the percentage of the CVMNK wild haplotype was significantly higher in isolates from participants aged $\geq 30$ years and $<30$ years, respectively. The association between the pfcrt 76T mutation and the host's age is controversial, where some studies have showed a significant association (May and Meyer 2003; Happi et al. 2006; Al-Mekhlafi et al. 2011) and others have reported no association (Atroosh et al. 2016; Acharya et al. 2018).

As regards a link with parasite density, the current study found that the percentages of the pfort 74I and 75E mutations and the CVIET mutant haplotype were significantly high in isolates from patients with a low parasitaemia level. Although the reason for these associations is unclear, previous studies reported significant associations of pfcrt mutations (particularly 76T) with 
parasitaemia and severity of infection (Al-Mekhlafi et al. 2011; Wélé et al. 2011; Atroosh et al. 2012; Acharya et al. 2018; Cuu et al. 2020). However, another study found no significant association (Mayengue et al. 2007; Atroosh et al. 2016).

In respect of a connection with residency, there was significant variation in the distribution of pfcrt polymorphism across the governorates involved in the current study. Almost all of the isolates from Aldair governorate were found to carry the mutant $p f c r t 76 \mathrm{~T}$ allele and over $90 \%$ of them were carrying the CVIET haplotype. Aldair borders Yemen to the south, and the highest prevalence of these markers was found in isolates from Yemeni patients. Studies conducted in Yemen have reported a very high prevalence of the pfcrt 76T mutation, which has reached fixation (100\%) in some areas (Al-Mekhlafi et al. 2011; Alareqi et al. 2016; Atroosh et al. 2016). Therefore, taking into account that Jazan region is the smallest region of Saudi Arabia, the reported variation can be attributed to the patients' residency. Nonetheless, the distinct variation in pfcrt 76T either between countries or within the same country has previously been reported, and most likely reflects variation in drug pressure between the countries (Kamugisha et al. 2012; Bamaga et al. 2015; Shah et al. 2015; Ndam et al. 2017; Ocan et al. 2019).

When interpreting the findings of the current study that have been discussed above, it is important to take bear in mind that the study has a few limitations. First, only codons 72 to 76 of the pfort gene were assessed, while other codons such as $97,220,271,326$, 353,356 , and 371 were not included. Indeed, point mutation 76T has become a hallmark of CQ resistance worldwide, and is widely used as an epidemiological tool for the monitoring of CQ resistance in large-scale field studies (Djimdé et al. 2001; Roux et al. 2021). Moreover, the cluster of mutations at codons 72 to 76 describes the evolution of the main pfcrt genotypes, including the SVMNT ancestral wild haplotype as well as the related mutated haplotypes such as the predominant and widespread CVIET haplotype (Awasthi et al. 2012). Second, a small number of blood samples was collected from female as compared to male participants as well as from some governorates and some nationalities. Nonetheless, the current study still provides important data about the distribution of pfcrt polymorphism in Jazan region after over a decade of CQ treatment withdrawal.

\section{Conclusion}

The current study provides important information on the status of CQ resistance in Jazan region, southwestern Saudi Arabia. The findings revealed a potential return of CQ-susceptible $P$. falciparum strains to the region. While the mutant $p f c r t 76 \mathrm{~T}$ allele and the triple-mutant haplotype CVIET were detected in $66.4 \%$ and $56.2 \%$ of the examined isolates, respectively, $33.6 \%$ of the isolates were found to be carrying the pfcrt K76 wild allele and the SVMNT wild haplotype. There is a consensus in the research community globally that ceasing the use of $\mathrm{CQ}$ in a region could result in the re-emergence of CQ-sensitive $P$. falciparum strains. This raises the possibility of the reintroduction of this safe and affordable drug, ideally in combination with another antimalarial drug, for falciparum malaria treatment. However, further studies to test this hypothesis are required.

Studies on the molecular markers of antimalarial drug resistance in Saudi Arabia are limited. Therefore, the findings from this study have significant implications for the monitoring of antimalarial drug resistance in the region. Consequently, the continuous molecular surveillance using the pfcrt 76T point mutation as a reliable marker for CQ resistance as well as further in vitro and ex vivo molecular studies would be highly beneficial. Furthermore, microsatellite loci analyses of larger number of samples set nationally to carefully evaluate $p f c r t$ polymorphisms in Saudi Arabia is strongly recommended.

\section{Declarations}

\section{Acknowledgements}

The authors are thankful to all participants for their voluntary participation in this study. The authors would also like to thank the administrative and laboratory staff from all participating healthcare facilities in Jazan region for their fruitful cooperation and support.

\section{Authors' contributions}

HMA AMM and AAA conceived and designed the study. AHG KAZ and HMA conducted the field survey and collection of samples and involved in the laboratory examination of samples. WMA performed the laboratory molecular experiments. WMA and HMA analysed the data. ZME provided logistic support for data collection and fieldwork. YLL provided logistic support for lab work. HMA wrote the 
paper. KYG AAA HAH AAM ZME and YLL revised the manuscript critically. The manuscript has been approved by all authors prior to submission. All authors approved the final version of the manuscript.

\section{Funding}

The work described here was funded by the Research Groups funding programme of the Deanship of Scientific Research, Jazan University (Vector-Borne Diseases Research Group, Grant no. RG-2-1).

\section{Availability of data and material}

All relevant data is available in the manuscript.

\section{Code availability}

Not applicable.

\section{Declarations}

\section{Ethical approval}

Ethical approval for the current study was obtained from the Ethics Committee of Jazan University (Ref. no. REC39/6-261). The study was also approved by the Ethics Committee of the Health Affairs Directorate of King Fahd Central Hospital, Jazan (Registry no. 086). Before data collection, the patients, and their guardians in case of children, were informed about the objectives of the study and their role. They were also informed that their participation was entirely voluntary and that they could withdraw at any time without giving any reasons whatsoever and without any consequences in respect of their health care. Then, written signed consent was obtained from the adult participants or from the children's parents or guardians. The patients were treated for malaria at the respective healthcare facilities according to the national malaria drug policy.

\section{Conflict of interest}

The authors declare that they have no competing interests.

\section{Consent for publication}

All authors have agreed and consented to publish the manuscript.

\section{References}

1. Acharya A, Bansal D, Bharti PK, Khan FY, Abusalah S, Elmalik A, ElKhalifa M, Mohapatra PK, Mahanta J, Sehgal R, Singh N, Sultan AA (2018) Molecular surveillance of chloroquine drug resistance markers (Pfcrt and Pfmdr1) among imported Plasmodium falciparum malaria in Qatar. Pathog Glob Health 112:57-62. https://doi.org/10.1080/20477724.2017.1399234.

2. Al Harthi SA (2007) Detection of drug resistance markers for chloroquine and pyrimethamine-sulfadoxine in Jazan area, Saudi Arabia using PCR and restriction digestion. J Egypt Soc Parasitol 37:17-30.

3. Alahmed AM, Munawar K, Khalil SMS, Harbach RE (2019) Assessment and an updated list of the mosquitoes of Saudi Arabia. Parasit Vectors 12:356. https://doi.org/10.1186/s13071-019-3579-4.

4. Alareqi LMQ, Mahdy MAK, Lau YL, Fong MY, Abdul-Ghani R, Mahmud R (2016) Molecular markers associated with resistance to commonly used antimalarial drugs among Plasmodium falciparum isolates from a malaria-endemic area in Taiz governorateYemen during the transmission season. Acta Trop 162:174-179. https://doi.org/10.1016/j.actatropica.2016.06.016.

5. Al Arishi HM, El Awad Ahmed F, Al Bishi LA (2001) Chloroquine-resistant Plasmodium falciparum malaria among children seen in a regional hospital, Tabuk, Saudi Arabia. Trans R Soc Trop Med Hyg 95:439-440. https://doi.org/10.1016/s00359203(01)90209-3.

6. Al-Hamidhi S, Mahdy MA, Al-Hashami Z, Al-Farsi H, Al-mekhlafi AM, Idris MA, Beja-Pereira A, Babiker HA (2013) Genetic diversity of Plasmodium falciparum and distribution of drug resistance haplotypes in Yemen. Malar J 12:244.

https://doi.org/10.1186/1475-2875-12-244. 
7. Alifrangis M, Lusingu JP, Mmbando B, Dalgaard MB, Vestergaard LS, Ishengoma D, Khalil IF, Theander TG, Lemnge MM, Bygbjerg IC (2009) Five-year surveillance of molecular markers of Plasmodium falciparum antimalarial drug resistance in Korogwe District, Tanzania: accumulation of the $581 \mathrm{G}$ mutation in the $P$. falciparum dihydropteroate synthase gene. Am J Trop Med Hyg 80:523527.

8. Al-Mekhlafi AM, Mahdy MA, Al-Mekhlafi HM, Azazy AA, Fong MY (2011) High frequency of Plasmodium falciparum chloroquine resistance marker (pfcrt T76 mutation) in Yemen: an urgent need to re-examine malaria drug policy. Parasit Vectors 4:94. https://doi.org/10.1186/1756-3305-4-94.

9. Al-Mekhlafi HM, Madkhali AM, Ghailan KY, Abdulhaq AA, Ghzwani AH, Zain KA, Atroosh WM, Alshabi A, Khadashi HA, Darraj MA, Eisa ZM (2021) Residual malaria in Jazan region, southwestern Saudi Arabia: the situation, challenges and climatic drivers of autochthonous malaria. Malar J 20:315. https://doi.org/10.1186/s12936-021-03846-4.

10. Alrajhi AA, Rahim I, Akood M, Hazmi M (1999) Chloroquine-resistant Plasmodium falciparum cerebral malaria in a chloroquinesusceptible area. J Infect Dis 180:1738-1741.

11. Ariey F, Fandeur T, Durand R, Randrianarivelojosia M, Jambou R, Legrand E, Ekala MT, Bouchier C, Cojean S, Duchemin JB, Robert V, Le Bras J, Mercereau-Puijalon O (2006) Invasion of Africa by a single pfcrt allele of South East Asian type. Malar J 5:34. https://doi.org/10.1186/1475-2875-5-34.

12. Atroosh WM, Al-Mekhlafi HM, Al-Jasari A, Sady H, Dawaki SS, Elyana FN, Al-Areeqi MA, Nasr NA, Abdulsalam AM, Subramaniam LR, Azzani M, Ithoi I, Lau YL, Surin J (2016) Different patterns of pfcrt and pfmdr1 polymorphism in Plasmodium falciparum isolates from Tehama region, Yemen. PeerJ 4:e2191. https://doi.org/10.7717/peerj.2191.

13. Atroosh WM, Al-Mekhlafi HM, Mahdy MA, Surin J (2012) The detection of pfcrt and pfmdr1 point mutations as molecular markers of chloroquine drug resistance, Pahang, Malaysia. Malar J 11:251. https://doi.org/10.1186/1475-2875-11-251.

14. Awasthi G, Satya Prasad GB, Das A (2012) Pfcrt haplotypes and the evolutionary history of chloroquine-resistant Plasmodium falciparum. Mem Inst Oswaldo Cruz 107:129-134. https://doi.org/10.1590/s0074-02762012000100018.

15. Babiker HA, Hastings IM, Swedberg G (2009) Impaired fitness of drug-resistant malaria parasites: evidence and implication on drug-deployment policies. Expert Rev Anti Infect Ther 7:581-593. https://doi.org/10.1586/eri.09.29.

16. Bakhiet AMA, Abdelraheem MH, Kheir A, Omer S, Gismelseed L, Abdel-Muhsin AA, Naiem A, Al Hosni A, Al Dhuhli A, Al Rubkhi M, Al-Hamidhi S, Gadalla A, Mukhtar M, Sultan AA, Babiker HA (2019) Evolution of Plasmodium falciparum drug resistance genes following artemisinin combination therapy in Sudan. Trans R Soc Trop Med Hyg 113:693-700. https://doi.org/10.1093/trstmh/trz059.

17. Balikagala B, Sakurai-Yatsushiro M, Tachibana SI, Ikeda M, Yamauchi M, Katuro OT, Ntege EH, Sekihara M, Fukuda N, Takahashi N, Yatsushiro S, Mori T, Hirai M, Opio W, Obwoya PS, Anywar DA, Auma MA, Palacpac NMQ, Tsuboi T, Odongo-Aginya El, Kimura E, Ogwang M, Horii T, Mita T (2020) Recovery and stable persistence of chloroquine sensitivity in Plasmodium falciparum parasites after its discontinued use in Northern Uganda. Malar J 19:76. https://doi.org/10.1186/s12936-020-03157-0.

18. Bamaga OA, Mahdy MA, Lim YA (2015) Survey of chloroquine-resistant mutations in the Plasmodium falciparum pfcrt and pfmdr-1 genes in Hadhramout, Yemen. Acta Trop 149:59-63. https://doi.org/10.1016/j.actatropica.2015.05.013.

19. Bin Dajem SM, Al-Farsi HM, Al-Hashami ZS, Al-Sheikh AA, Al-Qahtani A, Babiker HA (2012) Distribution of drug resistance genotypes in Plasmodium falciparum in an area of limited parasite diversity in Saudi Arabia. Am J Trop Med Hyg 86:782-788. https://doi.org/10.4269/ajtmh.2012.11-0520.

20. Bin Dajem SM, Al-Qahtani A (2010) Analysis of gene mutations involved in chloroquine resistance in Plasmodium falciparum parasites isolated from patients in the southwest of Saudi Arabia. Ann Saudi Med 30:187-192.

21. Bin Dajem SM, Al-Sheikh AA, Bohol MF, Alhawi M, Al-Ahdal MN, Al-Qahtani A (2011) Detecting mutations in PfCRT and PfMDR1 genes among Plasmodium falciparum isolates from Saudi Arabia by pyrosequencing. Parasitol Res 109:291-296. https://doi.org/10.1007/s00436-011-2251-5.

22. Cuu G, Asua V, Tukwasibwe S, Nsobya SL, Nanteza A, Kimuda MP, Mpimbaza A, Rosenthal PJ (2020) Associations between aminoquinoline resistance genotypes and clinical presentations of Plasmodium falciparum infection in Uganda. Antimicrob Agents Chemother 64:e00721-20. https://doi.org/10.1128/AAC.00721-20.

23. Dagnogo O, Ako AB, Ouattara L, Dago ND, Coulibaly DN, Touré AO, Djaman JA (2018) Towards a re-emergence of chloroquine sensitivity in Côte d'Ivoire? Malar J 17:413. https://doi.org/10.1186/s12936-018-2551-7. 
24. Djimdé A, Doumbo OK, Cortese JF, Kayentao K, Doumbo S, Diourté Y, Coulibaly D, Dicko A, Su XZ, Nomura T, Fidock DA, Wellems TE, Plowe CV (2001) A molecular marker for chloroquine-resistant falciparum malaria. N Engl J Med 344:257-263. https://doi.org/10.1056/NEJM200101253440403.

25. Feachem RGA, Chen I, Akbari O, Bertozzi-Villa A, Bhatt S, Binka F, Boni MF, Buckee C, Dieleman J, Dondorp A, Eapen A, Sekhri Feachem N, Filler S, Gething P, Gosling R, Haakenstad A, Harvard K, Hatefi A, Jamison D, Jones KE, Karema C, Kamwi RN, Lal A, Larson E, Lees M, Lobo NF, Micah AE, Moonen B, Newby G, Ning X, Pate M, Quiñones M, Roh M, Rolfe B, Shanks D, Singh B, Staley K, Tulloch J, Wegbreit J, Woo HJ, Mpanju-Shumbusho W (2019) Malaria eradication within a generation: ambitious, achievable, and necessary. Lancet 394:1056-1112. https://doi.org/10.1016/S0140-6736(19)31139-0.

26. Fidock DA, Nomura T, Talley AK, Cooper RA, Dzekunov SM, Ferdig MT, Ursos LM, Sidhu AB, Naudé B, Deitsch KW, Su XZ, Wootton JC, Roepe PD, Wellems TE (2000) Mutations in the $P$. falciparum digestive vacuole transmembrane protein PfCRT and evidence for their role in chloroquine resistance. Mol Cell 6:861-871. https://doi.org/10.1016/s1097-2765(05)00077-8.

27. Fogh S, Jepsen S, Effersoe P (1979) Chloroquine-resistant Plasmodium falciparum malaria in Kenya. Trans R Soc Trop Med Hyg 73:228-229. https://doi.org/10.1016/0035-9203(79)90220-7

28. Frosch AE, Laufer MK, Mathanga DP, Takala-Harrison S, Skarbinski J, Claassen CW, Dzinjalamala FK, Plowe CV (2014) Return of widespread chloroquine-sensitive Plasmodium falciparum to Malawi. J Infect Dis 210:1110-1114. https://doi.org/10.1093/infdis/jiu216.

29. Gadalla NB, Elzaki SE, Mukhtar E, Warhurst DC, El-Sayed B, Sutherland CJ (2010) Dynamics of pfcrt alleles CVMNK and CVIET in chloroquine-treated Sudanese patients infected with Plasmodium falciparum. Malar J 9:74. https://doi.org/10.1186/1475-28759-74.

30. General Authority for Statistics (GASTAT), Kingdom of Saudi Arabia. Census 2010. Available at: https://www.stats.gov.sa/en/13. Accessed 15 July 2021.

31. Ghalib HW, Al-Ghamdi S, Akood M, Haridi AE, Ageel AA, Abdalla RE (2001) Therapeutic efficacy of chloroquine against uncomplicated, Plasmodium falciparum malaria in south-western Saudi Arabia. Ann Trop Med Parasitol 95:773-779. https://doi.org/10.1080/0003498012011127.

32. Happi CT, Gbotosho GO, Folarin OA, Bolaji OM, Sowunmi A, Kyle DE, Milhous W, Wirth DF, Oduola AM (2006) Association between mutations in Plasmodium falciparum chloroquine resistance transporter and Plasmodium falciparum multidrug resistance 1 genes and in vivo amodiaquine resistance in Plasmodium falciparum malaria-infected children in Nigeria. Am J Trop Med Hyg 75:155-161.

33. Kamugisha E, Bujila I, Lahdo M, Pello-Esso S, Minde M, Kongola G, Naiwumbwe H, Kiwuwa S, Kaddumukasa M, Kironde F, Swedberg G (2012) Large differences in prevalence of Pfcrt and Pfmdr1 mutations between Mwanza, Tanzania and Iganga, Uganda-a reflection of differences in policies regarding withdrawal of chloroquine? Acta Trop 121:148151. https://doi.org/10.1016/j.actatropica.2011.11.004

34. Khan AQ, Pernaute-Lau L, Khattak AA, Luijcx S, Aydin-Schmidt B, Hussain M, Khan TA, Mufti FU, Morris U (2020) Surveillance of genetic markers associated with Plasmodium falciparum resistance to artemisinin-based combination therapy in Pakistan, 20182019. Malar J 19:206. https://doi.org/10.1186/s12936-020-03276-8.

35. Khattak AA, Venkatesan M, Jacob CG, Artimovich EM, Nadeem MF, Nighat F, Hombhanje F, Mita T, Malik SA, Plowe CV (2013) A comprehensive survey of polymorphisms conferring anti-malarial resistance in Plasmodium falciparum across Pakistan. Malar $\mathrm{J}$ 12:300. https://doi.org/10.1186/1475-2875-12-300.

36. Kublin JG, Cortese JF, Njunju EM, Mukadam RA, Wirima JJ, Kazembe PN, Djimdé AA, Kouriba B, Taylor TE, Plowe CV (2003) Reemergence of chloroquine-sensitive Plasmodium falciparum malaria after cessation of chloroquine use in Malawi. J Infect Dis 187:1870-1875. https://doi.org/10.1086/375419.

37. Lashin A, Al Arifi N (2012) The geothermal potential of Jizan area, southwestern parts of Saudi Arabia. Int J Phys Sci 7:664-675.

38. Laufer MK, Takala-Harrison S, Dzinjalamala FK, Stine OC, Taylor TE, Plowe CV (2010) Return of chloroquine-susceptible falciparum malaria in Malawi was a reexpansion of diverse susceptible parasites. J Infect Dis 202:801808. https://doi.org/10.1086/655659

39. Laufer MK, Thesing PC, Eddington ND, Masonga R, Dzinjalamala FK, Takala SL, Taylor TE, Plowe CV (2006) Return of chloroquine antimalarial efficacy in Malawi. N Engl J Med 355:1959-1966. https://doi.org/10.1056/NEJMoa062032. 
40. Lwanga SK, Lemeshow S, World Health Organization. Sample size determination in health studies : a practical manual. Geneva: World Health Organization; 1991. https://apps.who.int/iris/handle/10665/40062 Accessed 20 July 2021.

41. Madkhali AM, Al-Mekhlafi HM, Atroosh WM, Ghzwani AH, Zain KA, Abdulhaq AA, Ghailan KY, Anwar AA, Eisa ZM (2020) Increased prevalence of pfdhfr and pfdhps mutations associated with sulfadoxine-pyrimethamine resistance in Plasmodium falciparum isolates from Jazan Region, Southwestern Saudi Arabia: important implications for malaria treatment policy. Malar J 19:446. https://doi.org/10.1186/s12936-020-03524-x.

42. Malik GM, Khan AM, Abdalla SEA (1997) No response to chloroquine therapy in a case of a Saudi falciparum malaria. Saud Med J 18:99-100.

43. Malik GM, Seidi O, El-Taher A, Mohammed AS (1998) Clinical aspects of malaria in the Asir region, Saudi Arabia. Ann Saudi Med 18:15-17.

44. May J, Meyer CG (2003) Association of Plasmodium falciparum chloroquine resistance transporter variant T76 with age-related plasma chloroquine levels. Am J Trop Med Hyg 68:143-146.

45. Mayengue P, Kalmbach Y, Issifou S, Kremsner P, Ntoumi F (2007) No variation in the prevalence of point mutations in the pfcrt and pfmdr1 genes in isolates from Gabonese patients with uncomplicated or severe Plasmodium falciparum malaria. Parasitol Res 100:487-493. https://doi.org/10.1007/s00436-006-0287-8.

46. MEWA. Annual Statistical Book 2019. Riyadh: Ministry of Environment, Water, and Agriculture, 2019. Available at: https://mewa.gov.sa/ar/Pages/default.aspx Accessed 30 June 2021.

47. Ministry of Health. National Malaria Drug Policy. Riyadh: Ministry of Health, 2018. Available at: https://www.moh.gov.sa/Ministry/About/Health\%20Policies/029.pdf Accessed 10 July 2021.

48. Mulenga MC, Sitali L, Ciubotariu II, Hawela MB, Hamainza B, Chipeta J, Mharakurwa S (2021) Decreased prevalence of the Plasmodium falciparum Pfcrt K76T and Pfmdr1 and N86Y mutations post-chloroquine treatment withdrawal in Katete District, Eastern Zambia. Malar J 20:329. https://doi.org/10.1186/s12936-021-03859-z.

49. Mwai L, Ochong E, Abdirahman A, Kiara SM, Ward S, Kokwaro G, Sasi P, Marsh K, Borrmann S, Mackinnon M, Nzila A (2009) Chloroquine resistance before and after its withdrawal in Kenya. Malar J 8:106. https://doi.org/10.1186/1475-2875-8-106

50. Ocan M, Akena D, Nsobya S, Kamya MR, Senono R, Kinengyere AA, Obuku EA (2019) Persistence of chloroquine resistance alleles in malaria endemic countries: a systematic review of burden and risk factors. Malar J 18:76. https://doi.org/10.1186/s12936019-2716-z

51. Mekonnen SK, Aseffa A, Berhe N, Teklehaymanot T, Clouse RM, Gebru T, Medhin G, Velavan TP (2014) Return of chloroquinesensitive Plasmodium falciparum parasites and emergence of chloroquine-resistant Plasmodium vivax in Ethiopia. Malar $\mathrm{J}$ 13:244. https://doi.org/10.1186/1475-2875-13-244

52. Mohammed A, Ndaro A, Kalinga A, Manjurano A, Mosha JF, Mosha DF, van Zwetselaar M, Koenderink JB, Mosha FW, Alifrangis M, Reyburn H, Roper C, Kavishe RA (2013) Trends in chloroquine resistance marker, Pfcrt-K76T mutation ten years after chloroquine withdrawal in Tanzania. Malar J 12:415. https://doi.org/10.1186/1475-2875-12-415.

53. Ndam NT, Basco LK, Ngane VF, Ayouba A, Ngolle EM, Deloron P, Peeters M, Tahar R (2017) Reemergence of chloroquine-sensitive pfcrt K76 Plasmodium falciparum genotype in southeastern Cameroon. Malar J 16:130. https://doi.org/10.1186/s12936-017$1783-2$

54. Otienoburu SD, Maïga-Ascofaré O, Schramm B, Jullien V, Jones JJ, Zolia YM, Houzé P, Ashley EA, Kiechel JR, Guérin PJ, Le Bras J, Houzé S (2016) Selection of Plasmodium falciparum pfcrt and pfmdr1 polymorphisms after treatment with artesunateamodiaquine fixed dose combination or artemether-lumefantrine in Liberia. Malar J 15:452. https://doi.org/10.1186/s12936-0161503-3

55. Payne D (1987) Spread of chloroquine resistance in Plasmodium falciparum. Parasitol Today 3:241-246.

56. Roux AT, Maharaj L, Oyegoke O, Akoniyon OP, Adeleke MA, Maharaj R, Okpeku M (2021) Chloroquine and SulfadoxinePyrimethamine Resistance in Sub-Saharan Africa-A Review. Front Genet 12:668574. https://doi.org/10.3389/fgene.2021.668574.

57. Sahar S, Tanveer A, Ali A, Bilal H, Muhammad Saleem R (2015) Pfcrt Gene in Plasmodium falciparum field isolates from Muzaffargarh, Pakistan. J Arthropod Borne Dis 9:204-214.

58. Shah M, Omosun Y, Lal A, Odero C, Gatei W, Otieno K, Gimnig JE, ter Kuile F, Hawley WA, Nahlen B, Kariuki S, Walker E, Slutsker L, Hamel M, Shi YP (2015) Assessment of molecular markers for anti-malarial drug resistance after the introduction and scale-up of 
malaria control interventions in western Kenya. Malar J 14:75. https://doi.org/10.1186/s12936-015-0588-4.

59. Snow RW, Amratia P, Zamani G, Mundia CW, Noor AM, Memish ZA, Al Zahrani MH, Al Jasari A, Fikri M, Atta H (2013) The malaria transition on the Arabian Peninsula: progress toward a malaria-free region between 1960-2010. Adv Parasitol 82:205-251. https://doi.org/10.1016/B978-0-12-407706-5.00003-4.

60. Soliman RH, Garcia-Aranda P, Elzagawy SM, Hussein BE, Mayah WW, Martin Ramirez A, Ta-Tang TH, Rubio JM (2018) Imported and autochthonous malaria in West Saudi Arabia: results from a reference hospital. Malar J 17:286. https://doi.org/10.1186/s12936-018-2438-7.

61. Ursing J, Zakeri S, Gil JP, Björkman A (2006) Quinoline resistance associated polymorphisms in the pfcrt, pfmdr1 and pfmrp genes of Plasmodium falciparum in Iran. Acta Trop 97:352-356. https://doi.org/10.1016/j.actatropica.2006.01.002.

62. US-SABC. Working in Saudi Arabia: a labor market update. Vienna: US-Saudi Arabian Business Council, 2017. http://www.ussaudi.org/wp-content/uploads/2018/02/Labor-Industry-Brief-2017.pdf. Accessed 13 March 2021.

63. Wélé M, Djimdé AA, Guindo A, Beavogui AH, Traoré IZ, Sadou A, Blaise D, Diallo DA, Wellems TE, Doumbo OK (2011) High frequency of PfCRT 76T in two Malian villages and its prevalence in severe relative to non-severe malaria. Acta Trop 119:11-13. https://doi.org/10.1016/j.actatropica.2011.01.002.

64. Wellems TE, Plowe CV (2001) Chloroquine-resistant malaria. J Infect Dis 184:770-776. https://doi.org/10.1086/322858.

65. WHO. Microscopy for the detection, identification and quantification of malaria parasites on stained thick and thin blood films in research settings. Geneva: World Health Organization, 2015. Available at: https://apps.who.int/iris/handle/10665/163782 Accessed 01 December 2020.

66. WHO. World malaria report 2020. Geneva: World Health Organization; 2020. https://www.who.int/publications/i/item/9789240015791. Accessed 15 July 2021.

67. Wicht KJ, Mok S, Fidock DA (2020) Molecular Mechanisms of Drug Resistance in Plasmodium falciparum Malaria. Annu Rev Microbiol 74:431-454. https://doi.org/10.1146/annurev-micro-020518-115546.

\section{Tables}

Table 1 General characteristics of study participants $(n=235)$. 


\begin{tabular}{|lll|}
\hline Variables & Number & $\%$ \\
\hline Age* & $30.5 \pm 11.6$ & - \\
\hline Age groups & & \\
\hline$<18$ & 34 & 14.5 \\
\hline $18-30$ & 96 & 40.9 \\
\hline $31-40$ & 61 & 26.0 \\
\hline $41-50$ & 30 & 12.8 \\
\hline$\geq 51$ & 14 & 6.0 \\
\hline Gender & & \\
\hline Male & 193 & 82.1 \\
\hline Female & 42 & 17.9 \\
\hline Nationality & & \\
\hline Saudi Arabia & 80 & 34.0 \\
\hline Yemen & 69 & 29.4 \\
\hline Pakistan & 29 & 12.3 \\
\hline India & 21 & 8.9 \\
\hline Sudan & 11 & 4.7 \\
\hline Egypt & 9 & 3.8 \\
\hline Bangladesh & 8 & 3.4 \\
\hline Ethiopia & 5 & 2.1 \\
\hline Philippine & 2 & .9 \\
\hline Syria & 1 & .4 \\
\hline
\end{tabular}

* mean $\pm S D$

Table 2 Prevalence and distribution of pfcrt point mutations and haplotypes for $P$. falciparum isolates from Jazan region $(n=235)$. 


\begin{tabular}{|llll|}
\hline Marker & Type of mutations & Number & $\%$ \\
\hline Pfcrt 72 & Wild & 231 & 98.3 \\
\hline & Mutated & 4 & 1.7 \\
\hline Pfcrt 73 & Wild & 235 & 100 \\
\hline & Mutated & 0 & 0 \\
\hline Pfcrt 74 & Wild & 103 & 43.8 \\
\hline & Mutated & 132 & 56.2 \\
\hline Pfcrt 75 & Wild & 103 & 43.8 \\
\hline & Mutated & 132 & 56.2 \\
\hline Pfcrt 76 & Wild & 79 & 33.6 \\
\hline & Mutated & 156 & 66.4 \\
\hline CVMNK & Wild & 79 & 33.6 \\
\hline CVMNI & Single & 20 & 8.5 \\
\hline$\underline{\text { SVMNI }}$ & Double & 4 & 1.7 \\
\hline CVIET & Triple & 132 & 56.2 \\
\hline
\end{tabular}

Mutant alleles are bold and underlined.

Table 3 Distribution of pfcrt mutant alleles and haplotypes for $P$. falciparum isolates from Jazan region according to demographic factors and parasitaemia $(n=235)$. 


\begin{tabular}{|c|c|c|c|c|c|c|c|c|c|c|c|c|}
\hline \multirow[t]{2}{*}{ Marker } & \multicolumn{3}{|c|}{ Age group } & \multicolumn{3}{|l|}{ Sex } & \multicolumn{3}{|c|}{ Nationality } & \multicolumn{3}{|c|}{ Parasitaemia } \\
\hline & $<30$ & $\geq 30$ & $P$ & Females & Males & $P$ & Saudi & $\begin{array}{l}\text { Non- } \\
\text { Saudi }\end{array}$ & $P$ & Low & $\begin{array}{l}\text { Moderate- } \\
\text { to-high }\end{array}$ & $P$ \\
\hline $\begin{array}{l}P f C r t \\
72 \underline{\underline{S}}\end{array}$ & $\begin{array}{l}2 \\
(1.8)\end{array}$ & $\begin{array}{l}2 \\
(1.6)\end{array}$ & $0.979^{\dagger}$ & $1(2.4)$ & $\begin{array}{l}3 \\
(1.6)\end{array}$ & $0.548^{\dagger}$ & $\begin{array}{l}0 \\
(0.0)\end{array}$ & $\begin{array}{l}4 \\
(2.6)\end{array}$ & $0.302^{\dagger}$ & $\begin{array}{l}2 \\
(1.9)\end{array}$ & $2(1.5)$ & $0.892^{\dagger}$ \\
\hline $\begin{array}{l}P f C r t \\
74 !\end{array}$ & $\begin{array}{l}57 \\
(50.9)\end{array}$ & $\begin{array}{l}75 \\
(61.0)\end{array}$ & 0.120 & $\begin{array}{l}22 \\
(52.4)\end{array}$ & $\begin{array}{l}110 \\
(57.0)\end{array}$ & 0.585 & $\begin{array}{l}43 \\
(53.8)\end{array}$ & $\begin{array}{l}89 \\
(57.4)\end{array}$ & 0.591 & $\begin{array}{l}66 \\
(64.1)\end{array}$ & $66(50.0)$ & $0.031^{*}$ \\
\hline $\begin{array}{l}P f C r t \\
75 \underline{E}\end{array}$ & $\begin{array}{l}57 \\
(50.9)\end{array}$ & $\begin{array}{l}75 \\
(61.0)\end{array}$ & 0.120 & $\begin{array}{l}22 \\
(52.4)\end{array}$ & $\begin{array}{l}110 \\
(57.0)\end{array}$ & 0.585 & $\begin{array}{l}43 \\
(53.8)\end{array}$ & $\begin{array}{l}89 \\
(57.4)\end{array}$ & 0.591 & $\begin{array}{l}66 \\
(64.1)\end{array}$ & $66(50.0)$ & $0.031^{*}$ \\
\hline $\begin{array}{l}P f c r t \\
76 I\end{array}$ & $\begin{array}{l}67 \\
(59.8)\end{array}$ & $\begin{array}{l}89 \\
(72.4)\end{array}$ & $0.042^{*}$ & $\begin{array}{l}26 \\
(61.9)\end{array}$ & $\begin{array}{l}130 \\
(67.4)\end{array}$ & 0.498 & $\begin{array}{l}47 \\
(58.8)\end{array}$ & $\begin{array}{l}109 \\
(70.3)\end{array}$ & 0.075 & $\begin{array}{l}73 \\
(70.9)\end{array}$ & 83 (62.9) & 0.198 \\
\hline CVMNK & $\begin{array}{l}45 \\
(40.2)\end{array}$ & $\begin{array}{l}34 \\
(27.6)\end{array}$ & $0.042^{*}$ & $\begin{array}{l}16 \\
(38.1)\end{array}$ & $\begin{array}{l}63 \\
(32.6)\end{array}$ & 0.498 & $\begin{array}{l}33 \\
(41.2)\end{array}$ & $\begin{array}{l}46 \\
(29.7)\end{array}$ & 0.075 & $\begin{array}{l}30 \\
(29.1)\end{array}$ & 49 (37.1) & 0.198 \\
\hline CVMNI & $\begin{array}{l}8 \\
(7.1)\end{array}$ & $\begin{array}{l}12 \\
(9.8)\end{array}$ & 0.473 & $3(7.1)$ & $\begin{array}{l}17 \\
(8.8)\end{array}$ & $0.935^{\dagger}$ & $\begin{array}{l}4 \\
(5.0)\end{array}$ & $\begin{array}{l}16 \\
(10.3)\end{array}$ & 0.166 & $\begin{array}{l}5 \\
(4.9)\end{array}$ & 15 (11.4) & 0.076 \\
\hline$\underline{\text { SVMNI }}$ & $\begin{array}{l}2 \\
(1.8)\end{array}$ & $\begin{array}{l}2 \\
(1.6)\end{array}$ & $0.979^{\dagger}$ & $1(2.4)$ & $\begin{array}{l}3 \\
(1.6)\end{array}$ & $0.548^{\dagger}$ & $\begin{array}{l}0 \\
(0.0)\end{array}$ & $\begin{array}{l}4 \\
(2.6)\end{array}$ & $0.302^{\dagger}$ & $\begin{array}{l}2 \\
(1.9)\end{array}$ & $2(1.5)$ & $0.892^{+}$ \\
\hline CVIET & $\begin{array}{l}57 \\
(50.9)\end{array}$ & $\begin{array}{l}75 \\
(61.0)\end{array}$ & 0.120 & $\begin{array}{l}22 \\
(52.4)\end{array}$ & $\begin{array}{l}110 \\
(57.0)\end{array}$ & 0.585 & $\begin{array}{l}43 \\
(53.8)\end{array}$ & $\begin{array}{l}89 \\
(57.4)\end{array}$ & 0.591 & $\begin{array}{l}66 \\
(64.1)\end{array}$ & $66(50.0)$ & $0.031^{*}$ \\
\hline
\end{tabular}

All values are number (\%).

Pfcrt 73 was of wild type (V73) and thus, not included in the analysis.

Parasitaemia levels: low ( $<1,000$ parasites $/ \mu$ l of blood); moderate-to-high $(\geq 1,000$ parasites $/ \mu$ l of blood).

Mutant alleles are bold and underlined.

*Significant association $(P<0.05)$

† The difference was examined using Fisher's exact test (otherwise, Chi Square test was used).

\section{Figures}



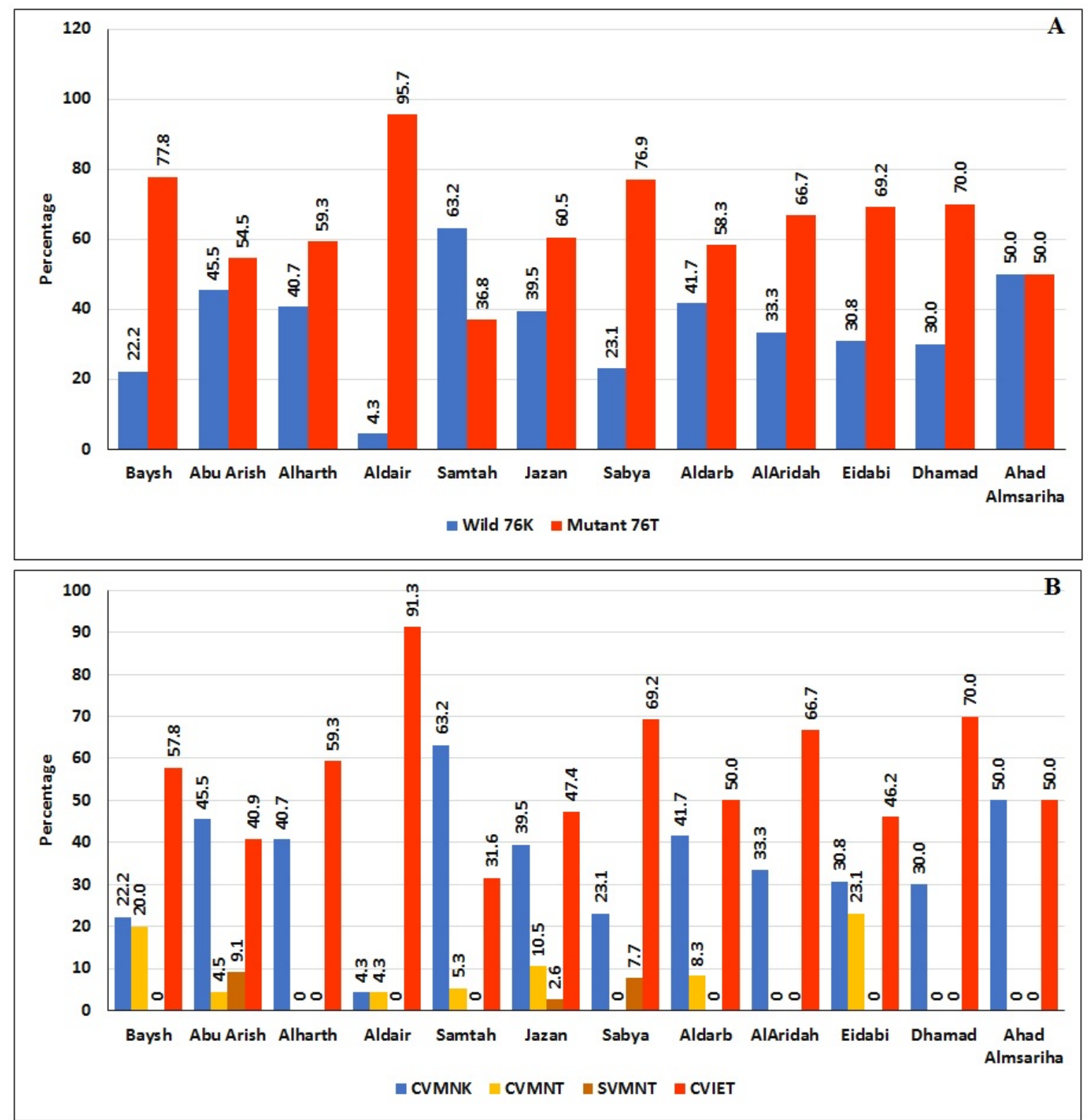

\section{Figure 1}

Distribution of pfcrt 76T point mutation and haplotypes for $\mathrm{P}$. falciparum isolates from Jazan region according to governorates involved in the study $(n=235)$. (A) pfcrt 76T mutation and (B) pfcrt haplotypes

\section{Supplementary Files}

This is a list of supplementary files associated with this preprint. Click to download.

- Supplementaryfile1.docx 